\title{
HPLC Analysis of Citric and Tartaric Acids in Fruit Nectars and Juices
}

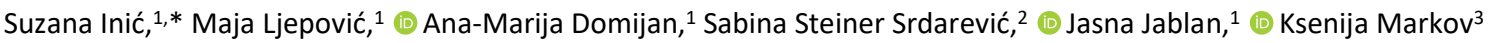

\footnotetext{
1 University of Zagreb, Faculty of Pharmacy and Biochemistry, A. Kovačića 1, Zagreb, Croatia

2 J. J. Strossmayer University of Osijek, Faculty of Dental Medicine and Health, Crkvena 21, Osijek, Croatia

3 University of Zagreb, Faculty of Food Technology and Biotechnology, Pierottijeva 6, Zagreb Croatia

* Corresponding author's e-mail address: sinic@pharma.hr
}

RECEIVED: July 3, 2020 * REVISED: September 16, 2020 * ACCEPTED: September 16, 2020

\begin{abstract}
The aim of this study was to estimate a level of citric and tartaric acids in fruit nectars $(n=17)$ and juices $(n=13)$ available on the Croatian market. For analysis reverse-phase HPLC with UV/Vis detector set at $214 \mathrm{~nm}$ was used. Mobile phase was phosphate buffer (50 mM, $\mathrm{pH}=2.80)$ at flow rate $0.5 \mathrm{~mL} \mathrm{~min}{ }^{-1}$. The method was linear $\left(r^{2}=0.9999\right)$. LoD was $0.01 \mathrm{~g} \mathrm{~L}^{-1}$, LoQ was $0.03 \mathrm{~g} \mathrm{~L}^{-1}$ and the intra-day along with the inter-day variability were up to $3 \%$. The level of citric and tartaric acids in fruit nectars ranged from 1.26 to $4.42 \mathrm{~g} \mathrm{~L}^{-1}$ and 0.68 to $0.86 \mathrm{~g} \mathrm{L^{-1 }}$ respectively, and in fruit juices ranged from 3.03 to $7.67 \mathrm{~g} \mathrm{~L}^{-1}$ and 3.09 to $4.68 \mathrm{~g} \mathrm{~L}^{-1}$, respectively. A higher level of citric acid in fruit juices than in fruit nectars was detected ( $p<0.05$; MannWhitney $U$ test). Six fruit juices contained a higher level of citric acid allowed by EU regulation implying the importance of monitoring concentrations of both acids in food products.
\end{abstract}

Keywords: citric acid, tartaric acid, fruit juices, monitoring, green chemistry, Croatian market.

\section{INTRODUCTION}

C ITRIC and tartaric acids are naturally occurring weak organic acids present in citrus fruits and grapes, respectively, and as such, are an important component of fruit beverages. Their presence determines the tartness and flavor of fruits as well as fruit beverages. ${ }^{[1]}$ In the wine industry the level of tartaric acid is controlled in order to influence the organoleptic properties of wine. ${ }^{[2]}$ Both acids are used extensively as food acidulants. Together with fumaric and phosphoric acids, citric and tartaric acids are used in the food industry to enhance beverage flavor. Except influencing on flavor, they have an impact on stability, nutrition, acceptability and storage quality of beverages. ${ }^{[3]}$ One example is the use of citric acid to prevent a color change of beverages that occur due to oxidation. ${ }^{[4]}$ Since citrus juices are easily modified, citric acid is used as a cheap ingredient to improve taste and increase shelf life. ${ }^{[5]}$

Some studies indicate that citric acid and tartaric acid can have unwanted effects on human health. For example, high concentrations of citric acid can affect tooth enamel. ${ }^{[6]}$ Ren et al. ${ }^{[7]}$ showed that high level of citric acid in orange juice reduced enamel's hardness by $84 \%$. In guinea pigs it is demonstrated that citric acid induces cough and a similar response is recorded in humans. ${ }^{[8]}$ It is noted for tartaric acid that high doses can give rise to acute kidney injury, gastrointestinal symptoms and cardiovascular collapse. ${ }^{[9,10]}$ Therefore, regulatory organizations, such as Commission regulation of EU, set up a maximum concentration of citric acid in fruit nectars and juices at $5.0 \mathrm{~g} \mathrm{~L}^{-1}$ and $3.0 \mathrm{~g} \mathrm{~L}^{-1}$, respectively and for tartaric acid is set at quantum satis, an amount not higher than necessary to achieve the purpose in accordance with good manufacturing practice (GMP). ${ }^{[11]}$ The Croatian legislation is completely harmonized with European laws. The Ordinance on fruit juices and similar products intended for human consumption in Croatia is based on the Food Act and it prescribes the conditions that fruit beverages on the Croatian market need to meet. ${ }^{[12]}$ Thus, it is important to monitor the level of organic acids for quality control purposes, as well as for meeting various laws and regulations in order to protect human health.

For the determination of organic acids in fruit juices several methods have been reported. ${ }^{[13-15]}$ High

(c) $\mathbf{B Y}$ This work is licensed under a Creative Commons Attribution 4.0 International License. 
performance liquid chromatography (HPLC) is a commonly employed technique for analyzing organic acids in various food and beverages. ${ }^{[16-20]}$ Therefore the first step of this study was to develop a fast, efficient, cost-effective and reproducible HPLC method for the determination of citric and tartaric acids in fruit beverage samples. Due to the high popularity of organic food, including fruit juices, the next step of this study was to compare the level of citric and tartaric acids in commercially available fruit nectars and fruit juices and to estimate possible exposure of the general population to these two acids. To our knowledge, no analysis has been made on the presence of these two organic acids in fruit beverages from the Croatian market.

\section{EXPERIMENTAL}

\section{Chemicals and Reagents}

Standards of citric (251275, Sigma-Aldrich) and tartaric acid (W304412, Sigma-Aldrich) were purchased from Sigma Chemical Co. (St. Louis, USA), while potassium dihydrogen phosphate $\left(\mathrm{KH}_{2} \mathrm{PO}_{4}\right)$, orthophosphoric acid, (o- $\mathrm{H}_{3} \mathrm{PO}_{4}$, min $85 \%)$ and HPLC grade methanol were purchased from Kemika (Zagreb, Croatia). For standard and sample preparation and preparation of mobile phase MilliQ water $\left(18.2 \mathrm{M} \Omega \mathrm{cm}^{-1}\right)$ was used.

\section{Standard Preparation}

Standard stock solution of citric and tartaric acids $\left(2.0 \mathrm{~g} \mathrm{~L}^{-1}\right)$ was prepared from granular citric acid and tartaric acid standard, respectively. Working standards in concentration range 0.1 to $1.0 \mathrm{~g} \mathrm{~L}^{-1}\left(0.1 \mathrm{~g} \mathrm{~L}^{-1}, 0.125 \mathrm{~g} \mathrm{~L}^{-1}, 0.25 \mathrm{~g} \mathrm{~L}^{-1}\right.$, $0.5 \mathrm{~g} \mathrm{~L}^{-1}, 0.75 \mathrm{~g} \mathrm{~L}^{-1}, 1.0 \mathrm{~g} \mathrm{~L}^{-1}$ ) were prepared fresh daily by dissolving stock solution in MilliQ water.

\section{Instrument}

The HPLC analysis was carried out using a Knauer HPLC (Berlin, Germany) consisted of an isocratic pump (model 64), UV/Vis detector (UV-1, Knauer, Berlin, Germany) and manual injector (Rheodyne 7010, sample loop $100 \mu \mathrm{L}$ ). The organic acids were separated on column LiChrospher RPC18, $5 \mu \mathrm{m}$ particle size $(125.0 \times 4.6 \mathrm{~mm}$, Merck, Darmstadt, Germany). Eurochrom 2000 Software (Knauer, Berlin, Germany) was used for data collection.

\section{Chromatographic Conditions}

As mobile phase, $50 \mathrm{mM}$ phosphate buffer solution at $\mathrm{pH}$ 2.80 was used. $50 \mathrm{mM}$ was prepared by dissolving $6.82 \mathrm{~g}$ of potassium dihydrogen phosphate in MilliQ water. The $\mathrm{pH}$ was adjusted to 2.80 with a calibrated pH meter (MP220, Mettler Toledo, Switzerland) by adding orthophosphoric acid. The mobile phase was degassed before use by ultrasonication for $30 \mathrm{~min}$. The UV/Vis detector wavelength was set at $214 \mathrm{~nm}$ and the mobile phase flow rate was $0.5 \mathrm{~mL} \mathrm{~min}{ }^{-1}$. Before and after analysis, HPLC grade methanol was used to prevent phase collapse.

\section{Sample Collection and Preparation}

In total 30 samples of fruit beverages were purchased from convenient stores, local supermarkets and organic food stores located in Zagreb, Croatia, in packages of $0.2-1 \mathrm{~L}$. Of that, 17 samples were fruit nectars (10 domestic and 7 imported) and 13 samples were fruit juices labelled as organic (4 domestic and 9 imported). According to EU legislation, nectars are obtained by adding water and sugar to fruit juices, while fruit juice is a product obtained from the fresh or preserved fruit.. ${ }^{[21]}$ According to declarations of obtained fruit nectar samples, 9 nectar samples were made of one sort of fruit (apple, cherry or orange) and 8 nectar samples were prepared of different mixed fruits (citrus, apple, red fruits, tropical fruits) (Table 1). From obtained fruit juices, according to the declaration, 8 samples were prepared of only one sort of fruit (apple, cherry, red grapes or orange). The other fruit juice samples were made of different mixed fruits (red grapes, apple, citrus, red fruits and tropical fruits) and 3 fruit juice samples were prepared of mixed fruits and carrot (Table 1). After being purchased, fruit nectars and juices samples were kept at $4^{\circ} \mathrm{C}$ before analysis.

Before the HPLC analysis, $1 \mathrm{~mL}$ of homogenized fruit beverages was taken and diluted with MilliQ water up to $10 \mathrm{~mL}$ (volume ratio, $1: 9$ ). In case that needed, the nectars and juices were filtered using $0.45 \mu \mathrm{m}$ membrane before dilution. To the HPLC $50 \mu \mathrm{L}$ of diluted sample was injected. Beverage samples were analyzed under the same conditions as standards. Chromatographic peaks were identified by comparing retention times of separated components in

Table 1. Samples of fruit nectars and fruit juices purchased on Croatian market and analyzed in this study.

\begin{tabular}{|c|c|c|c|}
\hline Fruit nectars & & $\begin{array}{c}\text { Organic } \\
\text { fruit juices }\end{array}$ & \\
\hline $\begin{array}{c}\text { Samples } \\
\text { (declared fruit) }\end{array}$ & Numeration & $\begin{array}{c}\text { Samples } \\
\text { (declared fruit) }\end{array}$ & Numeration \\
\hline Apple & $1-4$ & Apple & $1-4$ \\
\hline Cherry & 5 & Cherry & 5 \\
\hline Orange & $6-9$ & Red grapes & 6,7 \\
\hline Citrus & 10,11 & Orange & 8 \\
\hline $\begin{array}{l}\text { Citrus, Apple, } \\
\text { Red fruits }\end{array}$ & $12-14$ & $\begin{array}{l}\text { Red grapes, } \\
\text { Apple, Citrus }\end{array}$ & 9 \\
\hline Red fruits, Apple & 15,16 & Citrus, Carrot & 10,11 \\
\hline $\begin{array}{l}\text { Red fruits, } \\
\text { Tropical fruits }\end{array}$ & 17 & $\begin{array}{c}\text { Citrus, Apple, Red } \\
\text { fruits, Tropical } \\
\text { fruits, Carrot } \\
\text { Citrus, } \\
\text { Tropical fruits }\end{array}$ & 12 \\
\hline
\end{tabular}


chromatograms of beverage samples against known standards. Each beverage sample was analyzed in triplicate and quantitation values were obtained by applying their peak areas to the calibration curve.

\section{Statistical Analysis}

Statistical analysis of the data was performed with PrismGraphPad 8 (GraphPad Software, Inc., San Diego, $\mathrm{SAD})$. The Mann-Whitney $U$ test was used to analyze differences between levels of two acids in fruit nectars and fruit juices. Differences were considered significant for values of $p<0.05$.

\section{RESULTS AND DISCUSSION}

Citric and tartaric acids are widely used in the food and pharmaceutical industries as well as in wine production and play an important role in product characteristics like taste and aroma. Their quantification helps in determining product quality and authenticity. Reversed phase HPLC with UV-Vis detection is a common technique for organic acid analysis. ${ }^{[3,22]}$ In the present study, the concentration of citric and tartaric acids in fruit nectar and juice samples were determined by HPLC under reversed phase condition with UV/Vis detector. According to the literature, the wavelength was set at $214 \mathrm{~nm}$ and the mobile phase was phosphate buffer solution $(50 \mathrm{mM}$, $\mathrm{pH}=2.80) \cdot{ }^{[4,22]}$ Due to the low molecular weight of organic acids and their polarity, $100 \%$ aqueous buffer is required for their adequate retention. A phosphate buffer $\mathrm{pH}$ is adjusted to 2.80 to ensure that the organic acids remain protonated or neutral for the best interaction between the organic acids and the stationary phase of the RP-C18 column. ${ }^{[23]}$ The flow-rate of the mobile phase was set at $0.5 \mathrm{~mL} \mathrm{~min}-1$ for the whole run. Under these analytical conditions the satisfactory chromatogram of the baseline was obtained. The retention time was approximately 1.2 and 3.2 min for tartaric and citric acid standards, respectively and the whole analysis lasted for $10 \mathrm{~min}$. This indicates that the method is fast, simple and green because it is carried out in green condition (100\% aqueous mobile phase).
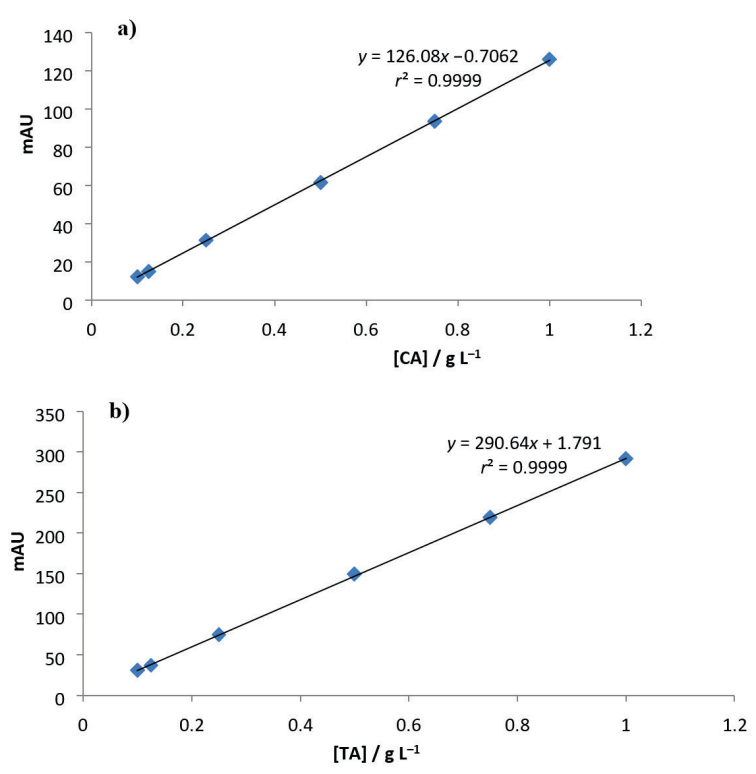

Figure 1. Calibration curve of: a) citric acid [CA] and b) tartaric acid [TA] standards prepared in MilliQ water (in range $0.1 \mathrm{~g} \mathrm{~L}^{-1}$ to $1.0 \mathrm{~g} \mathrm{~L}^{-1}$ ) and analyzed using developed HPLC-UV/Vis method. The standard at each concentration level was analyzed in four replicates. Linear regression parameters are given on each plot.

\section{Validation of the Method}

The linearity of the method was tested using citric and tar taric acid working standards prepared in MilliQ water in the concentration range from 0.1 to $1.0 \mathrm{~g} \mathrm{~L}^{-1}$ and each standard was analyzed in four replicates. The peak area responses were linear within the concentration range tested for both standards. The correlation coefficient of both calibration curves was $r^{2}=0.9999$ (Figure 1 ). The sensitivity of the method is given as limit of detection (LoD) and limit of quantification (LoQ). The values were calculated as LoD = $3.3 s_{y} / a$, and LoQ $=10 s_{y} / a$, where $s_{y}$ is the standard deviation of the linear regression intercept, and $a$ is the linear regression slope. The obtained results are summarized in Table 2.

Table 2. Validation parameters of developed HPLC-UV/Vis method for citric and tartaric acids standards prepared in MilliQ water.

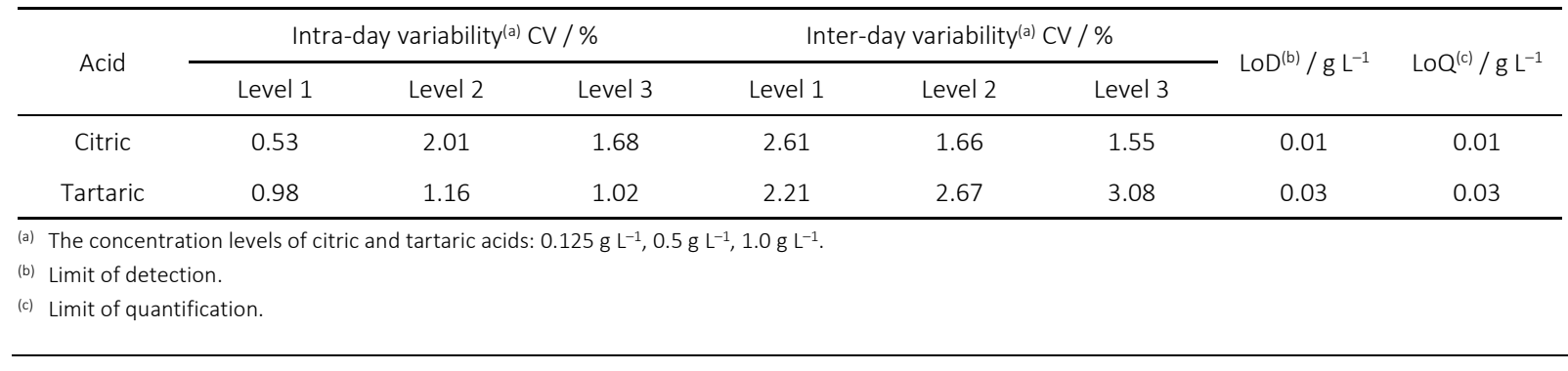


The repeatability (intra-day variability) was evaluated by determining citric and tartaric acid standards at three different concentrations $\left(0.125 \mathrm{~g} \mathrm{~L}^{-1}, 0.5 \mathrm{~g} \mathrm{~L}^{-1}\right.$, $1.0 \mathrm{~g} \mathrm{~L}^{-1}$ ) five repetitions each with an interval of an hour under the same experimental and lab conditions. The mean coefficient of variation (CV) for intra-day repetition was up to $2.0 \%$. The intermediate precision (inter-day variability) was tested by estimating citric and tartaric acid concentration at levels $0.125 \mathrm{~g} \mathrm{~L}^{-1}, 0.5 \mathrm{~g} \mathrm{~L}^{-1}, 1.0 \mathrm{~g} \mathrm{~L}^{-1}$ daily for three consecutive days. Inter-day variability (CV) was up to $3 \%$. These data indicate that the method is sensitive, reliable and precise for the determination of citric and tartaric acids in fruit beverage samples (Table 2).

\section{Analysis of Nectars and Fruit Juices}

For this study 17 fruit nectar samples were obtained in Zagreb convenient stores and local supermarkets. The level of citric acid determined by the developed HPLC method in samples of fruit nectar obtained in this study was in the range from 1.26 to $4.42 \mathrm{~g} \mathrm{~L}^{-1}$ (mean level was $2.75 \pm 1.01 \mathrm{~g} \mathrm{~L}^{-1}$ ) (Table 3$)$. In all analyzed fruit nectar samples the concentration of citric acid was under $5.0 \mathrm{~g} \mathrm{~L}^{-1}$ that is the concentration of citric acid allowed for fruit nectars by EU regulations. ${ }^{[11]}$ The highest level of citric acid $\left(4.42 \mathrm{~g} \mathrm{~L}^{-1}\right)$ was detected in orange nectar and the lowest in nectar declared to be made of red fruits and tropical fruits $\left(1.26 \mathrm{~g} \mathrm{~L}^{-1}\right)$. In the study of Cunha et al. ${ }^{[17]}$ conducted in Portugal that included samples of commercial fruit nectars ( $n=6$ ) of the citrus, pineapple and apple fruits the concentration of citric acid in three orange nectar samples ranged between 6.03 and $7.57 \mathrm{~g} \mathrm{~L}^{-1}$. Although in our study the level of citric acid was below regulation limits, the values reported by Cunha et al..17] were above the levels allowed by EU regulations indicating the importance of monitoring the level of citric acid in fruit nectars.

The tartaric acid level in the same fruit nectar samples was in the range of 0.68 to $0.86 \mathrm{~g} \mathrm{~L}^{-1}(0.68,0.83$, and $0.86 \mathrm{~g} \mathrm{~L}^{-1}$ ) (Table 3). In the majority of fruit nectar samples ( $n$ =14), declared to be prepared of only one fruit (apple, cherry, or orange) or of mixed fruits (citrus, apple, and red fruits), the tartaric acid was not detected. In the already mentioned study of Cunha et al. ${ }^{[17]}$ only one orange nectar sample contained a detectable tartaric acid level, and the concentration of tartaric acid was $0.363 \mathrm{~g} \mathrm{~L}^{-1}$. In this study, three fruit nectars prepared of mixed fruits contained the tartaric acid in concentration higher than reported by Cunha et al. ${ }^{[17]}$ probably due to the grape that was labeled to be present in these nectars. According to the obtained results of this study, it can be concluded that the level of citric and tartaric acids in fruit nectars on the Croatian market is low and at an acceptable level as allowed by EU regulations.

For this study, in Zagreb local and organic food stores, 13 samples of fruit juices labeled as organic were
Table 3. The level of citric and tartaric acids in fruit nectar samples detected by developed HPLC-UV/Vis method. The reported value of citric acid or tartaric acid in one sample is obtained from three repetitive measurements.

\begin{tabular}{|c|c|c|c|}
\hline \multicolumn{4}{|c|}{ Fruit nectars } \\
\hline $\begin{array}{c}\text { Samples } \\
\text { (declared fruit) }\end{array}$ & Numeration & $\begin{array}{c}\text { Citric acid / } \\
\mathrm{g} \mathrm{L}^{-1}\end{array}$ & $\begin{array}{c}\text { Tartaric acid } \\
/ \mathrm{g} \mathrm{L}^{-1}\end{array}$ \\
\hline Apple & $1-4$ & $1.9-2.84$ & n.d. \\
\hline Cherry & 5 & 3.88 & n.d. \\
\hline Orange & $6-9$ & $3.86-4.42$ & n.d. \\
\hline Citrus & 10,11 & $1.6,3.39$ & n.d. \\
\hline $\begin{array}{l}\text { Citrus, Apple, Red } \\
\text { fruits }\end{array}$ & $12-14$ & $1.42-2.08$ & n.d. \\
\hline Red fruits, Apple & 15,16 & $1.93,3.01$ & $0.83,0.68$ \\
\hline $\begin{array}{l}\text { Red fruits, Tropical } \\
\text { fruits }\end{array}$ & 17 & 1.26 & 0.86 \\
\hline
\end{tabular}

purchased. According to European legislation fruit juice is a product obtained from the fresh or preserved fruit with the allowed addition of citric acid.[21] The level of citric acid in collected samples of fruit juice detected by the developed method was in the range from 3.03 to $7.66 \mathrm{~g} \mathrm{~L}^{-1}$ (mean level was $4.56 \pm 1.51 \mathrm{~g} \mathrm{~L}^{-1}$ ) (Table 4 ). In seven fruit juice samples declared to be prepared of single fruit (apple, cherry or red grapes) citric acid was not detected. In the remaining six fruit juice samples the higher level of citric acid than $3.0 \mathrm{~g} \mathrm{~L}^{-1}$ as allowed by EU regulations for fruit juices was detected. These six fruit juices were made of Citrus species alone or in mixture with other fruits. Similar results were reported in a study by Cunha et al. ${ }^{[17]}$ In that study samples of commercial juices of citrus fruits, pineapple and apple were analyzed (in total 32 samples) and 6 samples of orange juice contained a higher level of citric acid (3.49$4.18 \mathrm{~g} \mathrm{~L}^{-1}$ ) than allowed by EU regulations. Scherer et al. ${ }^{[24]}$ reported a level of citric acid of 5.17 and $5.29 \mathrm{~g} \mathrm{~L}^{-1}$ in orange fruit juice samples obtained in the local stores in Brazil. Since on declaration of the fruit juice samples analyzed in this study with a high level of citric acid addition of synthetic citric acid was not stated, it can be concluded that detected citric acid originated only from citrus fruits. Previous studies by Karadeniz 2004,[25] Penniston et al. 2008,[26] and Nour et al. 2010,, ${ }^{[22]}$ indicate that citric acid is the major organic acid found in fresh citrus juices in the range from 6.05 to $73.94 \mathrm{~g} \mathrm{~L}^{-1}$. Organic acid accumulation in the cells of citrus fruits is a developmentally regulated process. Degree and timing vary greatly among species and varieties and is highly susceptible to agroclimate.[27]

The level of tartaric acid in obtained fruit juice samples was in the range from 3.09 to $4.68 \mathrm{~g} \mathrm{~L}^{-1}$ (3.09, 4.25, 4.68 and $\mathrm{g} \mathrm{L}^{-1}$ ) (Table 4). As expected, the highest level of tartaric acid was detected in two fruit juices declared as 
Table 4. The level of citric and tartaric acids in fruit nectar samples detected by developed HPLC-UV/Vis method. The reported value of citric acid or tartaric acid in one sample is obtained from three repetitive measurements.

\begin{tabular}{cccc}
\hline \multicolumn{4}{c}{ Organic fruit juices } \\
\hline $\begin{array}{c}\text { Samples } \\
\text { (declared fruit) }\end{array}$ & Numeration & $\begin{array}{c}\text { Citric acid / } \\
\text { g L }^{-1}\end{array}$ & $\begin{array}{c}\text { Tartaric acid / } \\
\text { g L }\end{array}$ \\
\hline Apple & $1-4$ & n.d. & n.d. \\
Cherry & 5 & n.d & n.d. \\
Red grapes & 6,7 & n.d & $4.25,4.68$ \\
Orange & 8 & 7.67 & n.d. \\
Red grapes, Apple, Citrus & 9 & 3.03 & 3.09 \\
Citrus, Carrot & 10,11 & $4.74,5.5$ & n.d. \\
Citrus, Apple, Red fruits, & 12 & 3.15 & n.d. \\
Tropical fruits, Carrot & 13 & 4.21 & n.d. \\
Citrus, Tropical fruits & 13 & &
\end{tabular}

n.d. - not detected.

organic red grape juices, one having $4.25 \mathrm{~g} \mathrm{~L}^{-1}$, and the other having $4.68 \mathrm{~g} \mathrm{~L}^{-1}$. Since on the label is not declared addition of tartaric acid, it can be assumed that tartaric acid is from grapes. These values for tartaric acid are in agreement with the results of the study of Soyer et al. ${ }^{[28]}$ In the study of Soyer et al. ${ }^{[28]}$ conducted in Turkey, the tartaric acid content was determined by HPLC in eleven grape juice samples and the level of tartaric acid ranged between 4.07 and $4.92 \mathrm{~g} \mathrm{~L}^{-1}$. In other samples of fruit juices analyzed in this study and declared to have other fruits than grapes, tartaric acid was not detected.

Additionally, results on the level of citric acid and tartaric acid between fruit nectars and fruit juices were compared. The detected level of citric acid in fruit juices was higher than in fruit nectars $\left(4.56 \pm 1.51 \mathrm{~g} \mathrm{~L}^{-1} \mathrm{vs.} 2.75 \pm\right.$ $1.01 \mathrm{~g} \mathrm{~L}^{-1} ; p<0.05$; Mann-Whitney $\mathrm{U}$ test). Since only three samples of fruit juices and fruit nectars had detectable level of tartaric acid, these results were not statistically compared. However, it can be observed that the level of tartaric acid $\left(4.25,4.68\right.$ and $\left.3.09 \mathrm{~g} \mathrm{~L}^{-1}\right)$ in fruit juices is higher than in fruit nectars $\left(0.83,0.68\right.$ and $\left.0.86 \mathrm{~g} \mathrm{~L}^{-1}\right)$. In general the level of both acids was higher in fruit juices than in fruit nectars. This can be attributed to better manufacturer control in fruit nectar production.

The results of this study indicate that the level of citric and tartaric acids in fruit nectars available on the Croatian market is below the concentration allowed by EU regulations and, as such, do not pose a threat to human health, confirming good manufacturing practice (GMP). In contrast, in organic fruit juice samples of citrus and mixed fruits higher level of citric acid than allowed by EU regulations was detected. A higher level of citric acid, detected in these juices, can be attributed to citric acid present in fruit rather than to the addition of synthetic citric acid to juices. Altogether higher level of both acids, citric and tartaric was detected in higher level in fruit juices than in fruit nectars. EU Directive regulate the level of citric acid in fruit beverages while for tartaric acid is set at quantum satis. However, possible negative impact on human health is implicated for both acids. Having in mind the popularity of organic food and beverages, a higher intake of organic fruit juices can pose a threat to human health since citric and tartaric acids can be present in various food and add to human exposure to these two acids. Therefore, the monitoring of the level of citric and tartaric acids in fruit beverages is needed in order to protect human health.

\section{CONCLUSION}

Developed HPLC method with UV/Vis detector is fast, reliable, sensitive and cost-effective for the determination of citric and tartaric acid in fruit nectar and juice samples. Because of the aqueous mobile phase the method can be considered green and suitable for routine analysis of these organic acids in fruit beverages. Analysis of fruit beverages samples reviled that fruit juices have higher level of both acids than fruit nectars. Moreover, the level of citric acid found in six of the thirteen commercial organic fruit juices was above the European regulation level. However, threshold value for tartaric acid is not regulated by EU Directive. Nevertheless, considering that the concentration of citric acid in six juice fruit samples exceeded the regulatory limit and due to the negative influence of high levels of citric and tartaric acid on human health, it is important to monitor concentrations of both acids in fruit beverages and other food products.

Acknowledgment. The authors greatly acknowledge financial support of the University of Zagreb.

\section{REFERENCES}

[1] G. Tyagi, D. K. Jangir, P. Singh, R. Mehrotra, R. Ganesan, E. S. R. Gopal, J. Food Sci. Technol. 2014, 51, 476-484.

https://doi.org/10.1007/s13197-011-0502-1

[2] V. J. Melino, K.L. Soole, C.M. Ford, BMC Plant Biol. 2009, 9, 145.

https://doi.org/10.1186/1471-2229-9-145

[3] G. Shui, L.P. Leong, J. Chromatogr. A, 2002, 977, 89-96.

https://doi.org/10.1016/S0021-9673(02)01345-6

[4] K. Weikle, Concordia College Journal of Analytical Chemistry, 2012, 3, 57-62.

[5] A. Sass-Kiss, M. Toth-Markus, M. Sass, Nutraceutical Beverages, 2004, 871, 24-34.

https://doi.org/10.1021/bk-2004-0871.ch003 
[6] Y. L. Wang, C. C. Chang, C. W. Chi, H. H. Chang, Y.C. Chiang, Y.C. Chuang, H. H. Chang, G. F. Huang, Y. S. Liao, C. P. Lin, Journal of the Formosan Medical Assotiation, 2014, 113, 850-856. https://doi.org/10.1016/j.jfma.2014.06.002

[7] Y. F. Ren, A. Amin, H. Malmstrom, J. Dent. 2009, 37, 424-431. https://doi.org/10.1016/j.jdent.2009.01.011

[8] S. Cui, I. Ito, H. Nakaji, T. Iwata, H. Matsumoto, T. Oguma, T. Tajiri, T. Nagasaki, Yoshihiro Kanemitsu, H. Izuhara, M. Mishima, A. Niimi Respir. Physiol. Neurobiol. 2019, 263, 1-8. https://doi.org/10.1016/j.resp.2019.02.002

[9] R. Naqvi, World J Nephrol, 2017, 6, 162-167. https://doi.org/10.5527/wjn.v6.i3.162

[10] D. E. Rusyniak, P. J. Durant, J. B. Mowry, J. A. Johnson, J. A. Sanftleben, J. M. Smith, J Med Toxicol, 2012, 9, 79-81. https://doi.org/10.1007/s13181-012-0255-x

[11] Commission Regulation (EU) No 1129/2011. https://eur-lex.europa.eu/eli/reg/2011/1129/oj

[12] Pravilnik o voćnim sokovima i njima sličnim proizvodima namijenjenim za konzumaciju, NN 48/2013. https://narodne-novine.nn.hr/clanci/sluzbeni/2013 _04_48_941.html

[13] F. O. Silva, V. Ferraz, Food Chem. 2004, 88, 609-612. https://doi.org/10.1016/j.foodchem.2004.05.002

[14] F. Chinnici, U. Spinabelli, C. Riponi, A. Amati, J. Food Compos. Anal. 2005, 18, 121-130. https://doi.org/10.1016/j.jfca.2004.01.005

[15] A. C. Silva, A. S. Lourenço, M. C. U. de Araujo, Food Chem. 2018, 266, 232-239. https://doi.org/10.1016/j.foodchem.2018.06.005

[16] M. Castellari, A. Versari, U. Spinabelli, S. Galassi, A. Amati, J. Liq. Chromatogr. Relat. Technol. 2000, 23, 2047-2056. https://doi.org/10.1081/JLC-100100472
[17] S. C. Cunha, J. O. Fernandes, I. M. Ferriera, Eur. Food Res. Technol. 2002, 214, 67-71. https://doi.org/10.1007/s002170100412

[18] E. Kafkas, M. Kosar, N. Turemis, K. H. C. Baser. Food Chem. 2006, 97, 732-736. https://doi.org/10.1016/j.foodchem.2005.09.023

[19] M. Mikulic-Petkovsek, V. Schmitzer, A. Slatnar, F. Stampar, R. J. Veberic, Food Sci. 2012, 77, C1064C1070.

https://doi.org/10.1111/j.1750-3841.2012.02896.x

[20] O. Marconi, S. Floridi, L. Montanari, J. Food Qual. 2007, 30, 253-266.

https://doi.org/10.1111/j.1745-4557.2007.00119.x

[21] Product names, definitions of products and characteristics, Directive 2012/12/EU of the European Parliament and of the Council https://www.legislation.gov.uk/eudr/2012/12/annex

[22] V. Nour, I. Trandafir, M. E. Ionica, Not. Bot. Hort. Agrobot. Cluj. 2010, 38, 44-48.

[23] J. Kowalski, B. Wittrig, Foods, Flavors \& Fragrances, 2007, Vol. 2.

[24] R. Scherer, A.C. Poloni, C.A. Ballus, A. Dillenburg, J. Teixeira, H. Teixeira, Food Chemistry, 2012, 135, 150-154.

https://doi.org/10.1016/j.foodchem.2012.03.111

[25] F. Karadeniz, Turk. J. Agric. For. 2004, 28, 267-271.

[26] K. L. Penniston, S. Y. Nakada, R. P. Holmes, D. G. Assimos, J. Endourol. 2008, 22, 567-570. https://doi.org/10.1089/end.2007.0304

[27] C. Canel, J. N. Bailey-Serres, M. L. Roose, Plant Physiol. 1995, 108, 1323-1324.

https://doi.org/10.1104/pp.108.3.1323

[28] Y. Soyer, N. Koca, F. Karadeniz, Journal of Food Composition and Analysis, 2003, 16, 629-636. https://doi.org/10.1016/S0889-1575(03)00065-6 